\title{
Expanding on Wabi-Sabi as a Design Resource in $\mathrm{HCl}$
}

\author{
Vasiliki Tsaknaki \& Ylva Fernaeus \\ Mobile Life@ KTH, Royal Institute of Technology \\ Stockholm, Sweden \\ \{tsaknaki, fernaeus\}@kth.se
}

\begin{abstract}
The material foundations of computer systems and interactive technology is a topic that gained an increased interest within the HCI community during the last years. In this paper we discuss this topic through the Japanese concept of Wabi-Sabi, a philosophy that embraces three basic realities of the material world: 'nothing lasts', 'nothing is finished', and 'nothing is perfect'. We use these concepts to reflect on four unique interactive artefacts, which all in different ways embrace aspects of Wabi-Sabi, in terms of their design gestalt, materiality, but also in terms of use practices. Further, we use our analysis to articulate three high-level principles that may help addressing the long-term realities faced in physical interaction design, and for the design of interactive systems in general.
\end{abstract}

\section{Author Keywords}

Interaction design; impermanence; incompleteness; imperfection; Wabi-Sabi; materiality; design practice

\section{ACM Classification Keywords}

H.5.m. Information interfaces and presentation (e.g., HCI):

Miscellaneous.

\section{INTRODUCTION}

A practical challenge for designers as well as users of interactive products today lies in how the engineering discourse of technology tends to promote values of designs to be finished, lasting, and perfect, while at the same time contradicting the same notions by technology that easily breaks or quickly becomes out of fashion. Several scholars have discussed this in relation to topics such as sustainability and obsolescence (e.g. [8,20,29] ) but also by further emphasising the concrete circumstances for crafting with interactive technology (e.g. [9,35,62]). Studying interaction design from a perspective of crafting has highlighted not only notions related to the skilled practice of working with specific tools and materials, but also the material foundations of design work in this domain [3,22]. An important aspect of this discussion concerns how the

Permission to make digital or hard copies of all or part of this work for personal or classroom use is granted without fee provided that copies are not made or distributed for profit or commercial advantage and that copies bear this notice and the full citation on the first page. Copyrights for components of this work owned by others than the author(s) must be honored. Abstracting with credit is permitted. To copy otherwise, or republish, to post on servers or to redistribute to lists, requires prior specific permission and/or a fee. Request permissions from Permissions@acm.org.

CHI'16, May 07 - 12, 2016, San Jose, CA, USA Copyright is held by the owner/author(s). Publication rights licensed to ACM. ACM 978-1-4503-

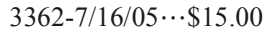

DOI: http://dx.doi.org/10.1145/2858036.2858459 design of interactive systems is physically tied to the material foundations that define possible interactions, computations and media expressions [5,11,15,67]. Developments in hardware for representing, storing and displaying electronic media have fundamentally affected not only the types of software that can be produced, but also how that software may be practically used and interacted with. Software and hardware is thereby "intimately connected to a cycle of mutual obsolescence", as phrased by Blevis ([8], p503). In this context it is increasingly relevant to reflect on how we, as a community concerned with design and user experiences, may provide advice and guidelines for new solutions to be not just attractive and easy to use, but also of relevance over time.

In this paper we use the philosophy of Wabi-Sabi $[33,50]$ to ground a discussion around how the above situation could be embraced in the design of interactive technology. WabiSabi is a traditional Japanese philosophy that "nurtures all that is authentic by acknowledging three simple realities: nothing lasts, nothing is finished, and nothing is perfect." ([50], p23). We explore the realities of Wabi-Sabi in interactive artefacts by first providing an extended overview of how its three themes have previously been addressed in HCI, followed by an articulation of our own understanding of the concept through analysing four distinct design cases.

Our analysis result in the formulation of three principles, which we suggest might help guiding designers who aim to approach Wabi-Sabi more concretely in their design work. The three principles each involves an element of contradiction, and are framed as: 1) Design for long-term interaction through conscious use of impermanent materials and media, 2) Approach perfection through explicitly unfinished designs, and 3) Engage with the richness of interactive expressions by embracing limitations in current technology.

Thus, we contribute by elaborating on Wabi-Sabi as a conceptual framework to reflect on crucial aspects that seem predominant in contemporary computing, but also as a practical resource to guide the design of new interactive solutions. Compared to previous work that has brought up Wabi-Sabi to the context of HCI [24,27] our aim is to provide a higher-level account of how this concept can be approached on a more conceptual level, beyond merely the surface appearance of designed systems and artefacts. 


\section{BACKGROUND}

As an aesthetic concept within the field of physical product design [30,44], Wabi-Sabi is sometimes used to describe objects with a family resemblance to traditional Japanese folklore, characterized through terms such as simplicity, patina, raw materials, and uneven and naturally shaped surfaces. In the area of computing, this notion of Wabi-Sabi has been introduced as a way of reflecting on design features primarily in the domain of physical interfaces and interaction. In their description of what they call organic interfaces, Holman \& Vertegaal for instance, use it to pose questions: "what might computers look like if they were designed with a little more wabi-sabi? More curved, like a piece of earthenware, more flexible, like a sheet of Japanese Washi rice paper and more delicate, like handmade knitwear?" ([24], p51). Wabi-Sabi has also been approached by Ikemya and Rosner in their articulation of worn media as a manifestation of wear among digital things [27].

In this paper we further elaborate the concept of Wabi-Sabi in HCI, but from a more philosophically oriented and holistic direction. The term Wabi-Sabi consists of two parts: Wabi refers to the essence of simplification, of cutting down the things to the important, whereas Sabi refers to the passage of time, and more specifically to the fact that the core of something remains the same, even though the facade or surface may change over time [50]. While Wabi resonates directly with standard principles of product- and interface design, such as the Bauhaus ideals of minimalism, Sabi has a less straightforward counterpart in (post) modern ideals of (predominantly Western) design thinking. However, the notion of Sabi is still very much present in traditional crafting practices observed also in non-Japanese contexts. Some examples include the resourceful use of material by a leather craftsman in Basel [64] and the central role of patina in repair work at a bookbinding workshop in Cambridge [55] - both observed for elaborating notions of craft in the context of HCI.

Thus, apart from being used to describe a physical form that has organic and delicate attributes, the concept of WabiSabi also embodies aspects of long-term deployment and use over time, which is an important concern for research in human-computer interaction. To emphasize this aspect, we will, in this paper, focus our analysis and discussion based on the three main themes of Wabi-Sabi, mentioned already in introduction: 'nothing lasts, nothing is finished, and nothing is perfect' [50]. We see this as forming a particularly well-articulated design philosophy, providing us with a lens through which to approach and guide a broader discussion around materiality in the context of interaction design, HCI, and computing at large.

Wabi-Sabi is a complex and rich philosophical concept, and we would like to acknowledge that we will be using it in a rather pragmatic way, based on simplified definitions as interpreted and summarized by predominantly western scholars and from a perspective of design theory [30,33,50]. Apart from being a guiding principle for design work, the concept of Wabi-Sabi is strongly associated with customs such as the Japanese tea ceremony, as well as with nature itself [33]. We would also like to emphasise that Wabi-Sabi is just one of many design philosophies that co-exist, and if studying Japanese high-tech product designs for example, this would not be the most prominent. Instead Wabi-Sabi to us, is better described as a globally occurring theme, or genre in contemporary product design, in which attention is directed towards traditional crafting and resourceful use of authentic and organic materials [44].

\section{THE THREE THEMES OF WABI-SABI IN HCI}

We will now delve briefly into how the three poetic themes of Wabi-Sabi - 'nothing lasts', 'nothing is finished', and 'nothing is perfect' - have been addressed in prior work within the field of HCI. Each of these three topics has a long existing discourse within the field, although most often using another vocabulary and without Wabi-Sabi as its guiding framework. Here we will give an overview of what we see as main topics within these works, separated into sections for each of the three themes.

\section{Impermanence - 'Nothing Lasts'}

Several scholars have stressed the importance of increasing the longevity and endurance of interactive products, most notably from a perspective of environmental sustainability (e.g. $[6,29,46])$. Others have highlighted the value of more long-term historical perspectives on interaction over all, such as Fernaeus et al. in their analysis of a 150 year old Jacquard loom still in use [13]. Even more broadly, Irwin, Kossoff and Tonkinwise [70], proposed the term transition design, as a way of framing design as dealing with societal transition towards more sustainable futures. The interaction design community within HCI has also highlighted several aspects around transience and temporality in accordance to the topics of materiality (e.g. [21,53]) and recent research on time-related issues in HCI [20,38]. In these, and other related works, concepts such as material traces [53], promoting quality and equality [7], or the ephemerality of social networks $[23,36]$ have been discussed as emergent throughout the lifetime of an interactive product or software system. Another direction from which impermanence has been discussed is through the lens of ephemeral user interfaces [10], designed from explicitly temporal materials such as ice or fog, taking the idea of impermanence to the extreme.

That the technology built, tested and reported on in the areas of electronics and computing is in constant development has also been discussed in terms of knowledge production. Hornbæk et al. [25] suggest that replacing old technologies with new in replication studies can help researchers reflect upon acquired knowledge on a specific research topic. In similar terms, the concept of an interaction design remake has been explored [4], pointing to 
the reality of technologies and experiences as shaped by changes in socio-technical contexts over time.

\section{Incompleteness - 'Nothing is Finished'}

The impermanent nature of technology is also related to the question of what is considered a finished interactive product [62]. In a research context, a finished or complete system or product may refer to a state of being ready to be adopted or deployed by users for user studies, in contrast to e.g. product design, where a finished product is ready to be mass-produced and released on the market [43]. In HCI, terms such as prototypes, probes or experiments are used to describe products that are part of a design exploration. Pierce and Paulos, for instance, use the term experiments to refer to a series of counterfunctional cameras they designed, since their aim was to explore this topic "without overly focusing on specific applications or finished, usable artifacts" ([48], p377).

However, all material entities are characterized by constant changes being either slow and subtle, or abrupt and drastic. This is also the case with interactive products, as they get filled with media content, get updated, or personalised. This was however not always the standard perspective taken in computational designs. An example is personal webpages, which in the 1990's often were accompanied with visual signage to indicate that they were 'under construction'. In reflecting on this, Rettberg concludes how this highlighted a tension between "the desire for completion that we had inherited from print and the constant flux of the web" ([51],p7). The early homepages could be seen as predecessors of today's blogs, were being 'unfinished', or having more updates to come, is rather a positive aspect of being 'live'. Computer systems being understood as in a constant state of development is now also evident e.g. in agile software development methodologies, and can also be illustrated by software companies, such as Adobe, who recently shifted their business model to sell subscriptions of a service, rather than licenses of products. An example from the other end of the spectrum is hardware hacking practices, practices of replacing or modding the physical casings or surfaces of interactive devices [61], or repair as an everyday design practice [38]. Thus, incompleteness from a perspective of being in progress is not to be read as bearing only negative connotations in the field of HCI, but rather as a reality that designers, companies and end users make use of actively as a resource. Embracing the idea of incompleteness in more positive terms, Seok et al. recently introduced a new design space of intentionally unfinished designs that help end-users solve their own problems, which they named Non-Finito Products [57].

\section{Imperfection - 'Nothing is Perfect'}

Perfection, within a traditional design discourse, has been associated with the properties of mass-produced objects in terms of form, shape, geometry or texture [34]. In that context, perfection is associated with ideals of symmetry, uniformity and lack of features acquired by use. Moving from mass production to personal fabrication, some designers and makers have now started to put the ideals of perfection as uniformity into question. In interaction design, there now seems to be an increasing number of makers and crafters inspired by the unique and thus 'imperfect' outcomes of making things by hand, or by using personal, local and small-scale fabrication tools (e.g. [17,43,69]). According to Ingold, the designer, as a creator or inventor of things, is the 'manager of imperfection' [28].

The notion of perfection gains relevance with increased emphasis on interaction design as a process of crafting, which can be described as "thinking through making things by hand" ([45], p2) or "the skilled manipulation of physical materials" ([52], p195). A major characteristic of a crafting process is the uniqueness of the produced outcomes, depended on the skilled work of the crafts specialist, but also on decisions taken on the spot. In a similar way, computer programming, and making in software in general, has been conceptualized as a crafting practice [41]. Similar to any crafting process, unintentional mistakes or decisions taken on the spot, based on circumstances in the digital tools, can lead to unique and unexpected outcomes, which greatly might impact the final design [15]. Along with the development of a rich variety of post-desktop computing devices, many alternative types of physical materials such as glass [56], leather and wood [64] or paper [42] become more common in the design of interactive artefacts. By integrating such types of materials in interaction design contexts, not only new types of crafting practices, but also different interactive qualities emerge, putting ideals of 'perfection' associated with mass-produced products into question. As mentioned by Vallgårda and Fernaeus, tangible and material computing thereby stresses the incomplete and imperfect reality of interaction design [66].

The notion of perfection also relates on a deep philosophical level to how user experience can be understood and approached by designers, e.g. as in McCarthy and Wright's pragmatically based account: "In a world of change, the same action can have different meaning and significance, as the context is always different. In an open world, all action is creative, a fresh use of intelligence producing something surprising and new every time." ([40], p71). In terms of experience, perfection thereby seems as nothing but a floating target - changing with practice, fashions and with technical development.

\section{FOUR DESIGN EXAMPLES}

We will here articulate our understanding of Wabi-Sabi in interaction design by presenting four distinctly different interactive objects, focusing on their respective design gestalt, materiality, but also their intended use. The presentation can be understood as a form of interaction critique [2], with explicit focus on how each of the objects can be interpreted in terms of impermanence, incompleteness and imperfection. These artefacts were chosen firstly because they all resonated with our 

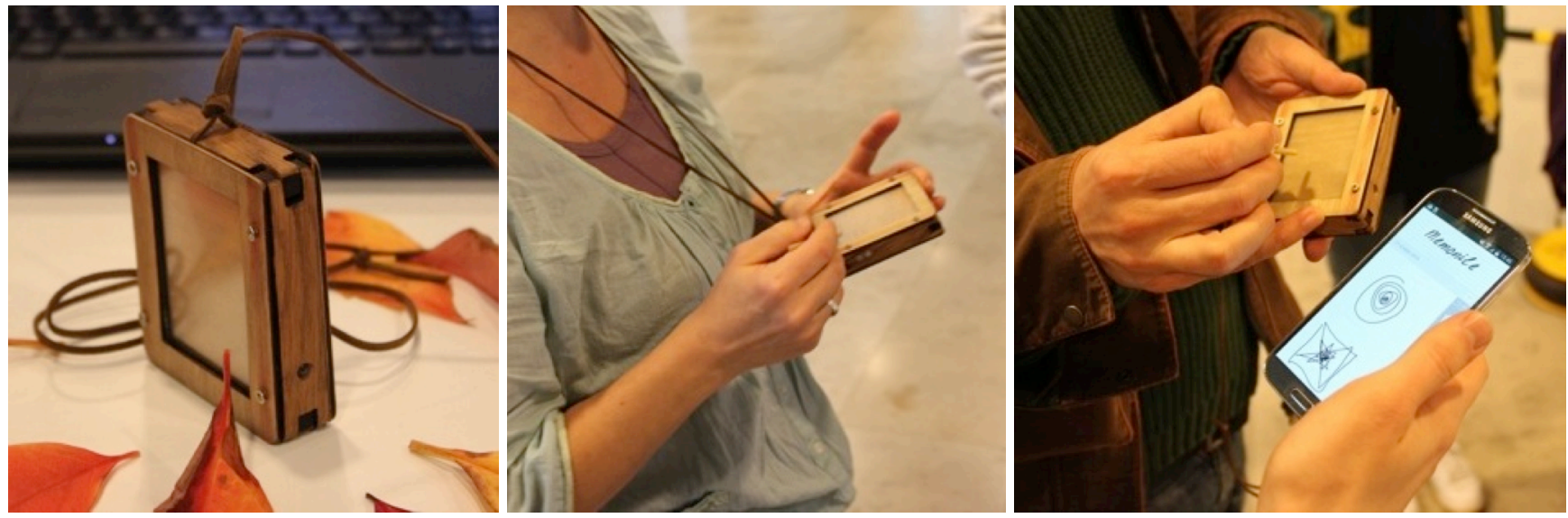

Figure 1. Memonile Necklace; a) overview picture of the device, b) device in use, c) device next to a smartphone, showing feed tracking the screenless doodles and gestures performed on the Memonile.

understanding of Wabi-Sabi, by presenting physical as well as interactive gestalts that emphasise aspects of repair, tweaking, and customisation. We also found them intriguing since their overall appearances depart in different ways from common norms in the design of interactive gadgets. Further, these artefacts were physically accessible to us, as we were able to experience their interactive qualities hands on, and discuss them with their makers. Finally, they cover a range of interactive arenas (design, performance, haptics, art), which allowed a discussion across different types of use settings.

The artefacts we will discuss here are:

- The Memonile, a note-taking device based on DIY aesthetics.

- Ajna, a complex musical cabinet, created in a bricolage fashion.

- Woody, an open-source haptic manipulation device.

- The Seaweed speaker, an exploration of physical form factors and interaction.

The analysis was conducted by articulating our subjective experience of interacting with each artefact, as well as from the descriptions given by their makers. This we used as a base for 'reading' the artefacts through the lens of the three themes presented above. The three realities highlighted by Wabi-Sabi were thereby used as a guide to foreground certain aspects of these designs, and to help us articulate different ways that these notions could be practically understood in relation to interactive products.

\section{Memonile}

The Memonile is a wireless interactive device worn as a necklace that can be used for sightlessly taking quick notes or doodles, which are stored as a feed on a mobile phone or other device (Figure 1). It was developed by a group of interaction design students during a three-week workshop, organized by our research group in the context of physical interaction design education [65]. Conceptualised by its designers as a kind of jewellery, it speaks to its explicit context of the maker culture, where the idea of personally manufactured technology, using tools such as laser cutters and latest microcontroller boards, are idealized, and possibly even worn on display. Its physical form factors and interactive gestalt are reminiscent of the since long obsolete Palm Pilot and similar devices of the late 1990's, which adds a quirky historical perspective to the design.

The physical object is made out of $3 \mathrm{~mm}$ plywood, cut using a laser cutter and assembled in a compact box that hangs around the neck by a leather cord. At the front of the box is a touch-sensitive input surface made of glass, interacted with a stylus pen, also made of wood. Inside the box is an Arduino compatible circuit board, the rFlea [60], which has a built-in Bluetooth Low Energy module in order to communicate wirelessly to the mobile phone of the person wearing the Memonile. When writing or doodling something on the screen, the word or the sketch is sent and saved as a feed on the user's mobile phone. This 'blindfolded' interaction with the input surface, without direct visual feedback on the device itself, adds a dimension of surprise, 'secrecy' and ambiguity to the performance of interaction.

The simple and rough 'quick and dirty' design of the Memonile points to a rather imperfect prototype. It is basically a wooden box assembled without any redundant elements or decorative details. At the same time, in terms of the physical form factors, the wooden parts assembled with screws in combination with the darker wooden surfaces, burnt from the laser beam, are traces inscribed from the fabrication process, which manifest deliberate and non-deliberate signs that become an important part of the design itself. The way it has been fabricated, also communicates the possibility to be disassembled in order to replace the electronics hosted inside the box, or change the glass input screen in case it breaks. In a similar way, the software was designed in an open-source fashion so that it can be programmed for different purposes, thus leaving the interaction open for personal appropriation and re-design. 

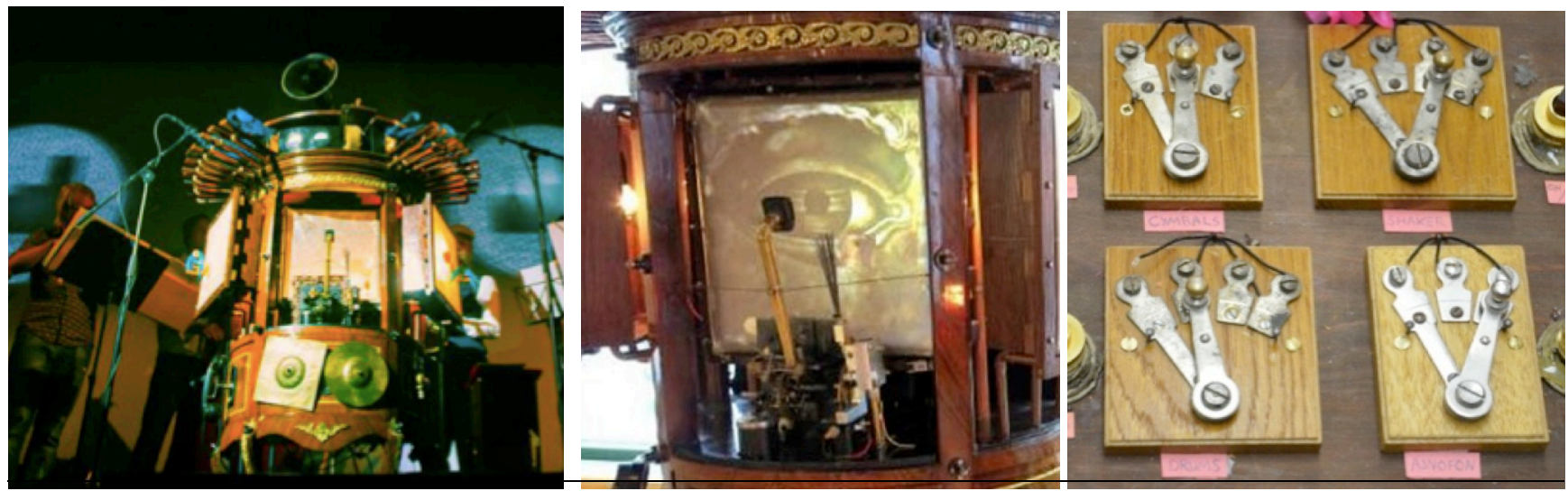

Figure 2. Ajna interactive musical cabinet; a) Ajna performing with orchestra, b) the main drum with projection, c) physical interface for controlling Ajna.

\section{Ajna}

Our second design case illustrates a more complex interactive construction (Figure 2). Ajna [16] is a humansized interactive musical object created by the art- and music collective I Skogen Ibland. Ajna is designed to perform along with a live orchestra in concert settings, but it has also been displayed in various music festivals and art gallery settings as an interactive music sculpture for audiences to interact with, using a variety of setups. Fernaeus and Vallgårda describe the design as "an obscure, musical bricolage, made from a heterogeneous collection of parts including electromechanical devices, old musical instruments, microcontrollers, wood, feathers, skin, motors, potentiometers - all hosted within the frame of a vintage rococo cabinet" ([16], p915). The different parts are put together as mechanical systems, which are controlled via midi signals, thus creating a complex physical form in combination with a rich musical soundscape.

In this design, we see Wabi-Sabi as represented through the on-going state of being 'in construction'. The artists are improving and adjusting the design before every show, this partly due to the fragile materials used for the separate parts, but also since they want to improve and test new ideas. This is the case not only for the physical structure, for instance that mechanical parts need to be re-adjusted or screws need to be tightened, but also in terms of software and audio used. Working as a composer, one of its designers constantly provides new media expressions for Ajna to perform. That the design is constantly changing increases the sense of liveness of Ajna, where each performance is unique and highly authentic.

The design is essentially a material assemblage, consisting of found and available objects which have been tailored to fit with a rather loose original idea shared and negotiated by two artists. Constructing Ajna from such a rich variety of materials and objects that each has its own unique history is also an important quality that makes the artefact seem like an organic being, with its own material history, unique visual appearance, and functionality.

Importantly, the reuse of artefacts was by the artists not expressed as for the purpose of eco design or environmental sustainability, instead this was rather of aesthetic and practical reasons, to make something that would work musically and also to fit with the cultural context of a live orchestra. The designers have thereby directed their efforts towards a rather narrow niche of cultural expression, in which e.g. clean white surfaces and blinking LED displays would make a less natural fit. This opened the design space for new solutions also in terms of interaction. The feathers of the marimba-like instrument at the top (see Figure 2a), were for instance not placed there merely for decorative purposes, but in order for the musicians to be able to read

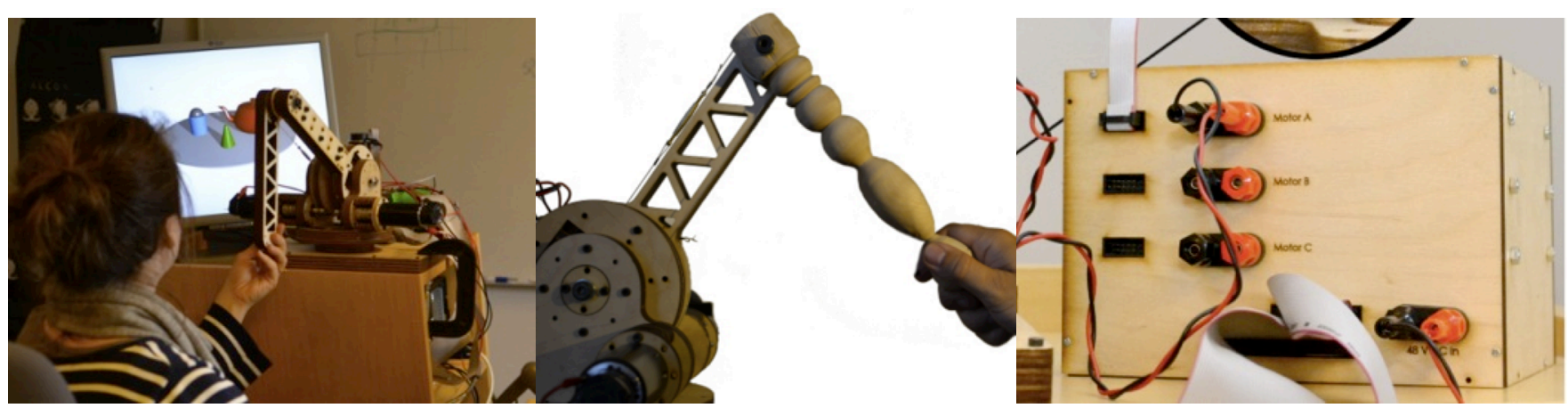

Figure 3. Woody, a haptic feedback device that can be physically adapted to fit the needs of specific haptic manipulation scenarios; a) overview of testing the device with on-screen model, b) the device with another design of arm, c) box with electrical interface. 
and follow the movements of Ajna while performing. Thus, the use of fragile organic physical matter is here shown to have functional as well as aesthetic uses in this specific interactive setting.

\section{Woody}

Woody (Figure 3) is an "open-source, open-hardware module-based kit" for spatial haptics [18]. Like other spatial haptic devices, it is based on a mechanical arm that a person can hold and manipulate, and through force feedback get a haptic experience of the shape and materials in 3D computer models. Such technology is used for instance in surgery simulations, for communication between blind, and other cases where physical feedback is central to the experience of interactive manipulation of media content.

One aspect that is unique about Woody is that the choice of wood as a material for the robotic arm means that designers, but also users, more easily can adapt the length and shape of the arm, and thereby more readily tune important parameters to fit a particular task or application (Figure 3b). With the classic 'set' design of similar devices, which are all based on an industrial design that cannot be modified, the interaction scenarios are limited to desktop settings with a very defined space for allowed gestures and manipulations.

The wood itself, and especially the production process of making use of laser cutting, also points to the quickness and ease that the device could be modified, and that the design itself is open for change. Wood may not seem the most durable material for this type of applications, but it does speak to common knowledge of sustainable practices of repair and use. Or, as expressed by one of its designers: 'they may paint it pink if they like to'. The need for a personalized device may be more important for a specific application, rather than a stable solution that may not be modified. Moreover, the makers of Woody chose not to encapsulate parts of the construction, specifically, the mechanical structure and wire rope power transmission, but leave them exposed. According to the authors, "this was intended to help designers focus more on designing for their application rather than problem solving through mechanical and electrical nuances and details" ([18], p134). Designers, in this case, refer to other people who like to use Woody as part of their own interactive setup.

The specific design embraces the fact that one solution may not fit all, and thus that the 'perfect' shape of a spatial haptic device is contextually dependent and shifts with specific applications.

\section{Seaweed Speaker}

Our last example is a simplistic case of a modded loudspeaker, made to emphasize the offline aspect of interacting with physical forms, as described by Esteves et al. [12]. This design was created by the first author in collaboration with a professional silversmith artist, as part of a six-month project exploring the intersection of jewellery and interaction design [63].

It functions as a mobile speaker, crafted in a sculptural form out of leather, which resembles a seaweed plant. On a surface level, the main function of this artefact could be read to provide another way of using and experiencing a mobile speaker as an electronic and mobile device. The Seaweed speaker connects to a device such as a mobile phone or a laptop, and can be either worn as a necklace (Figure 4a), placed on a surface (Figure 4b), or probably hung on the wall, leaving an increased openness or ambiguity in terms of where it can be placed, and accordingly, how it can be used or experienced as a device. But the user can also decide whether to fully expand it as a sculptural object, or entangle it in order to occupy less space. In the case of wearing the Seaweed speaker as a necklace, the user can bring the copper seashell, where the speaker is hosted, close to the ear to listen to the music, as shown in Figure 4c. Leather was chosen as a material to host the cables of the device because it can be easily deformed and shaped in different directions. The floppy leather parts can be placed in different ways, while no way is ever to be expected as better than any other. The organic shape reduces any expectations for symmetrical perfection
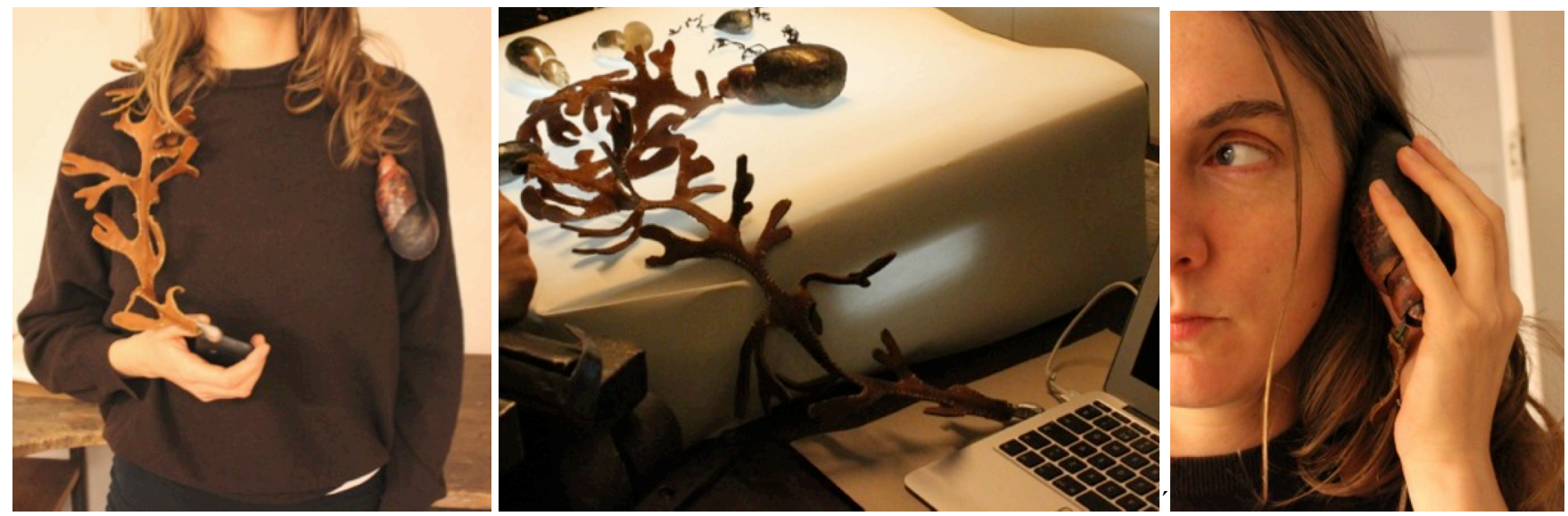

Figure 4. The Seaweed speaker; a) wearing the Seaweed speaker as a necklace, b) the Seaweed speaker with laptop, c) listening to the music from the copper shell-speaker. 
and points to the property of living things as growing and ever changing, pointing to the Wabi-Sabi notion of imperfection.

We also read this design as a commentary on the short-lived reality of most technical gadgets, where the mobile speaker/headphones may be one of the most common. Most of the cheap mobile speakers sold in the market will function only for a limited time, whereas the way they have been manufactured does not allow for repair. The carefully handcrafted copper, silver and leather parts, in a way intend to hide the electronic components, cables and battery, similar to most portable gadgets. But in contrast to most such devices, the entire electronic parts, which will likely be damaged at some point, have been made accessible in order to be replaced. The handcrafted case containing the circuit board is shaped as a mussel shell and has a small hinge and can open and close, providing access to the main electronics. In a similar way, the speaker with the cables attached to it is placed inside the copper spiral and can be removed by following around the spiral form. Thus, the way the Seaweed speaker has been crafted stresses, and probably takes to the extreme, the impermanent attributes of common electronic devices and gadgets.

\section{Insights from Analysing the Four Artefacts}

The most striking common feature of the designs above is probably how they all emphasise aspects of Wabi-Sabi through their physical properties. In our first interpretation, their surface appearances, made from organic materials, gave them a sense of liveness, for instance that they will age with time, which mapped well with our own preconception of Wabi-Sabi. This was also partly why these particular artefacts were selected for this study, and became an important part of our analysis. However, through our broadened insights from the analysis we would like to bring forth a more holistic perspective, including aspects of software, electronic behaviour, and user interaction.

The four design examples presented here all make explicit that the impermanent nature of software and hardware could be considered a design opportunity rather than only an obstacle. The Memonile with its lightweight prototype construction, Ajna through recycling of found objects, Woody through explicit instructions for modding and redesign, and the design for repairability in the Seaweed speaker. That said, it would probably be too drastic to say that these handcrafted interactive devices would be able to compete fully with mass-manufactured devices in terms of robustness, which often have had large groups of professional designers behind them, with much resources for testing and debugging. However, their explicit use of fragile materials and technologies, and that they thereby have been consciously designed to upgrade, repair, extend, and tweak, point to a shift in attitude compared to most other designs in this field.

Importantly, the physical materials chosen for each artefact, were not just interesting materials tried out together with electronics, but were actively chosen for practical reasons as for example the leather drums in the Ajna, or wood in the Woody. From a perspective of product design, these materials seem to have a greater potential for adaptation and repair, and also address a more varied view on culture and ever-changing contexts of use. The standard materials of plastic and metals used in most processes of massproduction are indeed often more robust and easier to massproduce, but also less straightforward to modify, repair, or to use in practices of making and crafting. A contradiction that the four design examples in different ways make explicit is thereby the mutual dependency of physical devices and interactive behaviour, in which, negative connotations of fragility and the positive discourse around constant progress can be seen as two sides of the same coin.

Further, all of the designs presented above point to a rather pluralistic view of interaction design, in which many parallel cultural values, aesthetic genres, and tastes are allowed to coexist. Taking Woody as an example, the 'openness' it allows for, embraces incompleteness in both hardware and software, through the possibility of making new variations. The possibility to replace or modify parts of the Woody in terms of hardware or software is assumed as a necessity in order to get closer to anything near 'perfection'. Similarly, this can be observed with the way the Memonile, Ajna and the Seaweed speaker have been designed. The Memonile that can be re-programmed, Ajna adapted to fit in the context of an orchestra, and the unusual gestalt of the Seaweed speaker.

There is no coincidence that all of the artefacts presented in this study are explicitly grounded in culture, but also in known limitations of current technology. In each of the examples, imperfections of current technology are used actively as a design resource, rather than a barrier for design. Looking at the Seaweed speaker for example, making accessible the electronic parts as things to be replaced, is core to its conceptual design and what it expresses, as a sculptural object. In Woody, the limitation of 'one size does not fit all' was the main motivation for its design, whereas the sightless interaction with the Memonile is what makes the interaction interesting as an interactive performance. Finally, the design case of Ajna represents a fine balance at the very limits of the technologically possible, which is also what made it into an impressively rich media art installation. Finally, it could be noted that all examples that we presented here illustrate an attitude of tinkering, reflected both in the making process but also as something that is welcomed and expected in use. Of course, such an attitude puts high demands on users as active cocreators and caretakers, which for sure would not be accepted by everyone. Yet, we see that these designs address an important desire, at least among certain user groups, where these use qualities are highly valued and expected.

Summarizing the insights from the critiques presented 
above, we see three emerging themes, each highlighting a paradoxical circumstance. Firstly, each of the four designs was intended as long-lasting object through customisation, repair and tweaking, while using rather fragile materials. Secondly, they all exhibit a design ideal that embraces repair and customisation, rather than the status of the brand new. Thirdly, they each manage to display rather visionary interactions, while engaging actively with limitations of current technology.

\section{DESIGNING INTERACTIONS WITH WABI-SABI}

Here we will further elaborate our understanding of WabiSabi in terms of how it could support reflection within the field of interaction design. We will structure this discussion around the three themes introduced in the analysis above. These themes, or paradoxes, could be seen as forming highlevel design principles for the domain of interactive systems:

1) Design for long-term interaction through conscious use of impermanent materials and media.

2) Approach perfection through explicitly unfinished designs.

3) Engage with the richness of interactive expressions by embracing limitations in current technology.

\section{Design for Long-term Interaction through Conscious Use of Impermanent Materials and Media}

The first topic we want to discuss is how conscious use of impermanent materials and media can be used actively as a way of guiding the design of long-term interaction. By impermanence we refer to the actual fragile properties of physical materials such as wood, glass screens and electronic parts, as well as of software built on unreliable foundations in terms of operating systems, service providers, or socio-technical infrastructure.

All physical artefacts change over time and with use, and eventually they will break. For the case of interactive systems, we are all familiar with this reality through disk spaces that get full, battery life getting shorter, buttons falling apart, screens that break and hard drives that simply stop working. It is also not uncommon that software files get corrupted or deleted, software running slower over time, and certain file formats or operating systems no longer get supported. Moreover, systems and functionality may get lost in the transition to new hardware platforms. When, for instance, the curators of MoMA recently decided to put together an archive exhibition of classic video games, one of their greatest challenges was that the physical controls needed to be remade, and also that software had to be reprogrammed, in order for the games to be playable using contemporary hardware [1]. With more active emphasis on the impermanent nature of interactive systems, we believe that more designs could be prepared for more lasting use.

As an extreme example, the Jacquard loom studied by Fernaeus et al. [13] had been persistently used for more than 150 years, although its construction was based entirely on 'fragile' materials such as wood, cardboards and cotton string. Even though this might seem like a paradox, that design was in the end probably more robust than even the sturdiest of smartphones of today. In a similar way as the Jaquard loom, designs based on this concept could allow for use practices that treat designed objects as live, accepting the need for some caretaking over time. An insight is that robust materials, such as plastic or metal, or software locked for modification or upgrades by end users, are commonly also difficult to repair.

In many ways the market embraces this reality, which is reflected in 'planned obsolescence', new technological gadgets, and constant needs for software updates. An everyday example is the repair of mobile phones, which has made specialized repair shops a thriving business. As a counter-reaction, DIY community blogs show instructions for how to repair a broken screen of an iPhone, for instance. This is just one of many examples of how the fragile nature of interactive products, both in hardware and software, is a reality that affects, apart from design practitioners, many other stakeholders.

Importantly, this principle will not necessarily solve, but rather highlight the problematic aspects of existing strategies such as planned obsolescence. This can also open new directions for more varied designs that embrace this reality. In HCI, this has been reflected in how materials such as paper [58], clay [54], glass [56] or even more fragile matter such as seeds or dried leaves [14] have been used to highlight this aspect of technology. For instance, Ikemiya and Rosner [27] describe prompted actions of breakage of ceramic objects can be used for reflecting on what they call worn media. Similarly, Pierce and Paulos constructed a series of cameras, which they describe as being "designed around the idea of requiring the user to physically break apart the camera in order to gain physical access to the digitally stored images' [49].

Thus, if accepting impermanence as a reality, then longevity and endurance might not even necessarily be a design target per se. The fragility and impermanence that are inherent properties of media might instead inspire new design directions and practices that treasure the ephemeral. One well-known example here is the online communication service Snapchat [71], in which a main feature is that content will be permanently deleted, after a time limit set by the user sending the content to recipients. This takes into consideration that impermanent videos or photos can engage users in a different way and be valued as shortlasting content. The value of this media lies exactly in its temporality, grounded in existing use practices and human values, rather than the assumed preference among users towards stored files that will be retrieved again and again. A more general example is the perceived promise of free, unlimited and permanent space as provided by the so-called 'cloud'. Storing our entire digital life stories permanently in 
digital form does not yet seem as a viable option, so other modes of looking at information and technology might be needed. The failed promise of eternal storage has also inspired other designs, e.g. Delete by Haiku [59] , in which old text messages may be creatively repurposed into a shortened poetic format, as a form of data compression.

As interaction designers, we might make a serious mistake when taking for example hardware platforms, interaction solutions, storage space or connectivity for granted. Even such widespread concepts as the 'mouse and keyboard', or 'double-clicking' are now quickly starting to get replaced by other interaction paradigms considered as mainstream. If the impermanent nature of interaction techniques on specific platforms, for example, were embraced more fully in design, then more care might be taken to find ways for systems to be kept alive. This could be considered important also on a broader scale, given the central role of interactive technology in our society and its potential value as part of our cultural heritage. Paradoxical as it may seem, making resourceful use of the impermanent properties of materials and media is a direction that we believe could possibly increase the potential of long-lived interactive systems.

\section{Approach Perfection through Explicitly Unfinished Designs}

Our second theme concerns how explicitly unfinished or incomplete designs could be a way of working towards pleasing the specific needs of different users. The 'timeless perfection' as proposed in early modernism and industrial design through planar surfaces and strict minimalist geometric forms, and which has been inherited also to graphical interfaces, could be argued to neglect some of the multi-faceted nature of culture as changing over time, between contexts and societies. Our reading of Wabi-Sabi proposes that it is through the particular intentions and skills of the designer, crafts person, or programmer, but also the tools available a given moment, and finally the cultural and historical grounding, through which a negotiation of perfection could potentially be achieved. Given the global context of our field of studies, one may ask if timeless perfection' is even a sensible target for interaction design. And if so, what would such a design be like?

In the design examples presented above, this question is approached through designs that provide the possibility to be improved, altered and repaired over time and for different contexts of interaction and use. This direction links the notion of imperfection to uniqueness, previously discussed in product design in relation to injection moulding as a method of production [47] or from a material perspective, linking imperfection with graceful aging [32]. What we mean here is the imperfections inherent in organic materials and in handcrafted objects, rather than to a negative connotation of something that is 'not right'. This also points to the nature of making as a process of compromises and decisions taken on the spot, in contrast to a process of mass-production, which can be considered as resulting in 'perfect' products.

However, there is a danger to read this paradox as potentially welcoming attitudes such as 'anything goes', 'adhocism', or sloppiness in design, which is rather contradictory to the traditional crafting practices that WabiSabi is fundamentally drawing on. Rather than taking responsibilities away from the judgments of designers, the aim here is to shift these to further acknowledge the potential re-designs and evolvement that may occur within use and after deployment.

The incompleteness that is inherent in a design process, but also in the way interactive products are designed and experienced by users, is mirrored by this quote from the Wabi-Sabi philosophy: "All things are incomplete. [...] All things [...] are in constant, never-ending state of becoming or dissolving" ([33], p49). Thus, the fact that things are constantly becoming, changing and transforming is an important aspect of reality, which successful long-lived systems will have to be designed for.

The idea of incompleteness, as interpreted through the philosophical concept of Wabi-Sabi speaks to current needs for tailorability and modifications, also in software. In that way, an interactive artefact can always be transformed and 'evolve' over time and through usage, or adapt to fit with new needs or interests. Still, the look of the 'new' is obviously to be idealised by an industry who aims to sell more products, and thus may be a challenge to address concretely in terms of industrial design practice. However, we believe that the notion of the new is now complemented by allowing practices of adapting, appropriating or updating, and for users to relate to interactive products in terms of long-term service.

\section{Engage with the Richness of Interactive Expressions by Embracing Limitations in Current Technology}

Our third proposal for how to approach Wabi-Sabi in interaction design is to embrace the limitations in current technology, as a way to engage with the full potential of interactive expressions. According to the tradition of WabiSabi 'good design is design based on the materials at hand' [31]. This view relates the concept of Wabi-Sabi to that of bricolage, which has been discussed as a making process that rather than being primarily concept-driven, is guided by a dialogue with the available materials, tools and resources, and thereby more explicitly allows for unique and unpredictable results [37]. Interaction design relies fundamentally on current technological advances and computational materials, ranging from circuit boards to software systems and other peripherals. Working knowledge of such technology, based on active experimentation with the media expressions they may produce, is often necessary in order to achieve desired user experiences.

Looking at technological artefacts from such a perspective 
is grounded on the idea that "technologies must be understood phenomenologically, as belonging in different ways to our experience and use of technologies as a humantechnology relation, rather than abstractly conceiving of them as mere objects" [26]. We believe that we have to use the possibilities and limitations of current technology in order to design rich interactions, rather than relying on visions of what technologies we might have as a resource in the future. Considering the limitations and imperfections of current technology in tandem with materials and software, there could be new framings and understandings concerning design methods, which complement approaches that start from a perspective of concepts and visions.

To us, this principle points towards a direction of 'honesty', in terms of the material properties of electronics, but also in terms of digital media being inherently limited. However, rather than referring to authenticity of materials as opposed to e.g. skeuomorphs [68], this links directly to the three paradoxes presented in this paper, i.e. that artefacts will break, they will not last and the design may never be 'finished'. Such a perspective might potentially reflect a pessimistic outlook that would not strive for new solutions, visions, and readiness for what comes next. However, looking at the second paradox presented above, leaving a design 'unfinished' can be a way to allow for integrating new technological solutions, to ideally make them both backward- and forward compatible.

\section{CONCLUSION}

In this paper we used the Japanese philosophy of Wabi-Sabi to reflect on the material circumstances for contemporary computing, and more specifically for interaction design. We did this by first presenting an overview on how the three themes of Wabi-Sabi - 'nothing lasts', 'nothing is finished', and 'nothing is perfect' - have been previously addressed in HCI. Additionally, we presented a reflective account of four examples of uniquely designed interactive artefacts, which all in different ways embrace the three themes.

From an engineering perspective, the three themes of WabiSabi could probably read as pessimistic, as problems to solve or realities that should be strived to overcome. However, through our deepened engagement with these concepts we found each of the themes as not bound to negative connotations, but rather to be highlighting cultural values that are relevant to all practices, ranging from design, to crafting, and practices of use. This led us to formulate three high-level design principles, which can be used as a way to practically engage with Wabi-Sabi in design work, or as an analytical lens to reflect on any other interactive product or system. We proposed that a way to design for long-term interaction could be through conscious use of impermanent materials and media, but also that 'perfection' could be approached through explicitly unfinished designs that allow for modifications and repair. Additionally, by embracing the limitations in current technology, it is possible to engage fully with the richness of interactive expressions.

The above directions are pointing to alternative ways of discussing the long-term impact of digital media on the one hand, but they also speak to a more general desire for more authentic interactive products on the other, which is essentially what the philosophy of Wabi-Sabi is about. The first has to do with the equilibrium between designing for long-term interaction, while at the same time embracing the reality that the software and hardware of each artefact will evidently become obsolete. The second paradox proposed to embrace artefacts as 'unfinished' entities, as a way to eventually come closer to a 'perfect' design. Finally, the third theme was about accepting and making creative use of given technological limitations.

We would also like to note that although we found the examples presented here as highly intriguing, these should not be read as direct proposals to turn into mass production, but rather as reflections on how interaction designs could be allowed to exist also outside of the limited frames of capitalist structures. This topic opens up broader discussions in relation to socio-economic and political agendas, from considering various modes of open source as an attitude and political stance. With the democratization of knowledge that the Internet, social networks and globalization brought, people learn to fix things themselves, but also to exchange services and knowledge on topics that cover a vast spectrum. Such a direction supports alternative modes of making and sharing, in contrast to supporting ideals of the 'ready-made', which are more related to traditional exchange systems. Even though we find this topic very important to be further addressed, it goes beyond the scope of the study presented here.

Finally, we believe that looking at interactive products from a Wabi-Sabi perspective, or using Wabi-Sabi as a resource in design practice, is an important direction that can raise more discussions around the material aspects of computing and interactive technologies, placing them in their cultural and time-specific contexts.

\section{ACKNOWLEDGMENTS}

The research has been funded by the Arts and Crafts project at Mobile Life Vinn Excellence Centre, with a grant from Vinnova. We would like to thank all the designers and artists of the four artefacts discussed in this paper for their insightful comments.

\section{REFERENCES}

1. Paola Antonelli. 2013. The New Frontiers of Design. Opening plenary keynote, CHI'13.

2. Jeffrey Bardzell. 2009. Interaction criticism and aesthetics. Proceedings of the 27th international conference on Human factors in computing systems - CHI 2357. http://doi.org/10.1145/1518701.1519063 
3. Shaowen Bardzell, Daniela K. Rosner, and Jeffrey Bardzell. 2012. Crafting quality in design. Proceedings of the Designing Interactive Systems Conference on - DIS '12, ACM Press, 11. Retrieved September $25, \quad 2015 \quad$ from http://dl.acm.org/citation.cfm?id=2317956.2317959

4. Moa Bergsmark and Ylva Fernaeus. 2016. From Patchwork to Appliqué: Reflections from an Interaction Design Remake. Proceedings of the International Conference on Tangible, Embedded and Embodied Interaction (TEI '16), ACM.

5. Jean-françois Blanchette. 2011. A Material History of Bits. Journal of the American Society for Information Science and Technology 62, 6: 10421057.

6. Eli Blevis, Kevin Makice, William Odom, et al. 2007. Luxury \& new luxury, quality \& equality. Proceedings of the 2007 conference on Designing pleasurable products and interfaces - DPPI '07, ACM Press, 296. Retrieved September 25, 2015 from

http://dl.acm.org/citation.cfm?id=1314161.1314188

7. Eli Blevis and Erik Stolterman. 2007. Ensoulment and Sustainable Interaction Design. IASDR07, Hong Kong Polytechnic University, 1-23.

8. Eli Blevis. 2007. Sustainable interaction design: invention \& disposal, renewal \& reuse. In Proceedings of the SIGCHI Conference on Human Factors in Computing Systems (CHI '07). ACM, New York, NY, USA, 503-512. DOI=http://dx.doi.org/10.1145/1240624.1240705.

9. Leah Buechley and Hannah Perner-Wilson. 2012. Crafting technology. ACM Transactions on Computer-Human Interaction 19, 3: 1-21. http://doi.org/10.1145/2362364.2362369

10. Tanja Döring, Axel Sylvester, and Albrecht Schmidt. 2013. A design space for ephemeral user interfaces. Proceedings of the 7th International Conference on Tangible, Embedded and Embodied Interaction - $\quad$ TEI '13: 75. http://doi.org/10.1145/2460625.2460637

11. Paul Dourish and Melissa Mazmanian. 2011. Media as Material: Information Representations as Material Foundations for Organizational Practice. International Symposium on Process Organization Studie, 1-24.

12. Augusto Esteves, Michelle Scott, and Ian Oakley. 2013. Supporting offline activities on interactive surfaces. TEI '13, ACM Press, 147. http://doi.org/10.1145/2460625.2460648

13. Ylva Fernaeus, Martin Jonsson, and Jakob Tholander. 2012. Revisiting the jacquard loom: threads of history and current patterns in HCI. In Proceedings of the SIGCHI Conference on Human Factors in Computing Systems (CHI '12). ACM, New York, NY, USA, 1593-1602. DOI=http://dx.doi.org/10.1145/2207676.2208280

14. Ylva Fernaeus, Martin Murer, Vasiliki Tsaknaki, and Jordi Solsona Belenguer. 2013. Handcrafting electronic accessories using "raw" materials. TEI '14, ACM Press, 369-372. http://doi.org/10.1145/2540930.2567906

15. Ylva Fernaeus and Petra Sundström. 2012. The material move how materials matter in interaction design research. In Proceedings of the Designing Interactive Systems Conference (DIS '12). ACM, New York, NY, USA, 486-495. DOI $=10.1145 / 2317956.2318029$ http://doi.acm.org/10.1145/2317956.2318029

16. Ylva Fernaeus and Anna Vallgårda. 2014. Ajna: negotiating forms in the making of a musical cabinet. In Proceedings of the 2014 conference on Designing interactive systems (DIS '14). ACM, New York, NY, USA, 915-924. DOI=http://dx.doi.org/10.1145/2598510.2600883

17. Patrick Tobias Fischer, Eva Hornecker, and Christian Zoellner. 2013. SMSlingshot: an expert amateur DIY case study. Proceedings of the International Conference on Tangible, Embedded and Embodied Interaction TEI '13, ACM Press, 916. http://doi.org/10.1145/2460625.2460627

18. Jonas Forsslund, Michael Yip, and Eva-Lotta Sallnäs. 2015. WoodenHaptics: A Starting Kit for Crafting Force-Reflecting Spatial Haptic Devices. Proceedings of the Ninth International Conference on Tangible, Embedded, and Embodied Interaction - TEI '15, ACM Press, 133-140. http://doi.org/10.1145/2677199.2680595

19. Verena Fuchsberger, Martin Murer, and Manfred Tscheligi. 2015. Time and Design. TEI '14, ACM Press, $581-586$ http://doi.org/10.1145/2677199.2687911

20. Silke Gegenbauer and Elaine M. Huang. 2012. Inspiring the design of longer-lived electronics through an understanding of personal attachment. DIS '12, ACM Press, 635. http://doi.org/10.1145/2317956.2318052

21. Elisa Giaccardi, Elvin Karana, Holly Robbins, and Patrizia D'Olivo. 2014. Growing traces on objects of daily use: a product design perspective for HCI. In Proceedings of the 2014 conference on Designing interactive systems (DIS '14). ACM, New York, NY, USA, 473-482. DOI=http://dx.doi.org/10.1145/2598510.2602964 
22. Shad Gross, Jeffrey Bardzell, and Shaowen Bardzell. 2013. Structures, forms, and stuff: the materiality and medium of interaction. Personal and Ubiquitous Computing 18, 3: 637-649. http://doi.org/10.1007/s00779-013-0689-4

23. Richard Harper, Eryn Whitworth, and Ruth Page. 2012. | Harper | Selected Papers of Internet Research. Selected Papers of Internet Research 2. Retrieved September 25, 2015 from http://spir.aoir.org/index.php/spir/article/view/8

24. David Holman and Roel Vertegaal. 2008. Organic user interfaces. Communications of the ACM 51, 6: 48. http://doi.org/10.1145/1349026.1349037

25. Kasper Hornbæk, Søren S. Sander, Javier Andrés Bargas-Avila, and Jakob Grue Simonsen. 2014. Is once enough?: on the extent and content of replications in human-computer interaction. CHI '14, ACM Press, 3523-3532. http://doi.org/10.1145/2556288.2557004

26. Don Ihde. 1995. Postphenomenology: Essays in the Postmodern Context. Retrieved May 15, 2015 from https://books.google.com/books?hl=el\&lr=\&id=149 PYEDFSbgC\&pgis $=1$

27. Miwa Ikemiya and Daniela K. Rosner. 2013. Broken probes: toward the design of worn media. Personal and Ubiquitous Computing 18, 3: 671683. http://doi.org/10.1007/s00779-013-0690-y

28. Tim Ingold and Social Anthropology. 2013. Making: Anthropology, Archaeology, Art and Architecture. Routledge.

29. Heekyoung Jung, Shaowen Bardzell, Eli Blevis, James Pierce, and Erik Stolterman. 2011. How Deep Is Your Love: Deep Narratives of Ensoulment and Heirloom Status. 5, 1: 59-71.

30. Andrew Juniper. 2011. Wabi Sabi: The Japanese Art of Impermanence. Tuttle Publishing. Retrieved September 22, 2015 from https://books.google.com/books?id=objWAgAAQB AJ\&pgis $=1$

31. Anne Marie Kanstrup and Ellen Christiansen. 2006. Selecting and evoking innovators. NordiCHI '06, ACM Press, 321-330. http://doi.org/10.1145/1182475.1182509

32. Elvin Karana, Owain Pedgley, and Valentina Rognoli. 2013. Materials Experience: fundamentals of materials and design. Butterworth-Heinemann.

33. Leonard Koren. 1994. Wabi-Sabi: For Artists, Designers, Poets and Philosophers. Stone Bridge Press, Berkeley, California.

34. William Lidwell, Kritina Holden, and Jill Butler. 2003. Universal Principles of Design: 100 Ways to
Enhance Usability, Influence Perception, Increase Appeal, Make Better Design Decisions, and Teach Through Design. Rockport Publishers. Retrieved September 25, 2015 from https://books.google.com/books?id=juX1nCMWkP $\mathrm{kC} \&$ pgis $=1$

35. Rikard Lindell. 2013. Crafting interaction: The epistemology of modern programming. Personal and Ubiquitous Computing 18, 3: 613-624. Retrieved March 18, 2015 from http://link.springer.com/10.1007/s00779-013-06876

36. Siân Lindley, Robert Corish, Elsa Kosmack Vaara, Pedro Ferreira, and Vygandas Simbelis. 2013. Changing perspectives of time in HCI. CHI EA '13, ACM Press, 3211. http://doi.org/10.1145/2468356.2479649

37. Panagiotis Louridas. 1999. Design as bricolage: anthropology meets design thinking. Design Studies 20, 6: 517-535. http://doi.org/10.1016/S0142694X(98)00044-1

38. Leah Maestri and Ron Wakkary. 2011. Understanding repair as a creative process of everyday design. Proceedings of the 8th ACM conference on Creativity and cognition - C\&C'11, ACM Press, 81. http://doi.org/10.1145/2069618.2069633

39. Ramia Mazé. 2007. Occupying Time: Design, technology and the form of interaction. Axl Books.

40. John McCarthy and Peter Wright. 2004. Technology as Experience. MIT Press.

41. Malcolm McCullough. 1998. Abstracting Craft: The Practiced Digital Hand. Retrieved September 24, $2015 \quad$ from https://books.google.com/books?hl=el\&lr=\&id=Pc wH1 WricJEC\&pgis $=1$

42. David A. Mellis, Sam Jacoby, Leah Buechley, Hannah Perner-Wilson, and Jie Qi. 2013. Microcontrollers as material. TEI '13, ACM Press, 83. http://doi.org/10.1145/2460625.2460638

43. David A. Mellis. 2013. Do-it-yourself electronic products and the people who make them. International Conference on Tangible, Embedded and Embodied Interaction (TEI '13), ACM Press, 357. http://doi.org/10.1145/2460625.2460692

44. Boye De Mente. 2006. Elements of Japanese Design. Retrieved September 24, 2015 from https://books.google.com/books?hl=el\&lr=\&id=jy7 Y2wTBXUwC\&pgis=1 
45. Nithikul Nimkulrat. 2012. Hands-on Intellect: Integrating Craft Practice into Design Research Introduction : IJDesign 6, 3: 1-14.

46. William Odom and James Pierce. 2009. Improving with age. Proceedings of the 27th international conference extended abstracts on Human factors in computing systems - CHI EA '09, ACM Press, 3793. Retrieved September 25, 2015 from http://dl.acm.org/citation.cfm?id=1520340.1520573

47. Giuseppe Salvia, Francesca Ostuzzi, Valentina Rognoli and Marinella Levi. 2012. The value of imperfection in sustainable design: The emotional tie with perfectible artefacts for longer lifespan. Retrieved from Academia.edu

48. James Pierce and Eric Paulos. 2014. Counterfunctional things. DIS '14, ACM Press, 375-384. http://doi.org/10.1145/2598510.2598522

49. James Pierce and Eric Paulos. 2015. Making Multiple Uses of the Obscura 1C Digital Camera. CHI '15, ACM Press, 2103-2112. http://doi.org/10.1145/2702123.2702405

50. Richard R. Powell. 2004. Wabi Sabi Simple. Adams Media.

51. Jill Walker Rettberg. 2013. Blogging. Polity.

52. Daniela K. Rosner and Kimiko Ryokai. 2009. Reflections on craft: probing the creative process of everyday knitters. In Proceedings of the seventh ACM conference on Creativity and cognition (C\&C '09). ACM, New York, NY, USA, 195-204. DOI=http://dx.doi.org/10.1145/1640233.1640264

53. Daniela K. Rosner, Miwa Ikemiya, Diana Kim, and Kristin Koch. 2013. Designing with traces. Proceedings of the SIGCHI Conference on Human Factors in Computing Systems - CHI '13, ACM Press, 1649. Retrieved January 7, 2016 from http://dl.acm.org/citation.cfm?id=2470654.2466218

54. Daniela K. Rosner, Miwa Ikemiya, and Tim Regan. 2015. Resisting Alignment: Code and Clay. In Proceedings of the Ninth International Conference on Tangible, Embedded, and Embodied Interaction (TEI '15). ACM, New York, NY, USA, 181-188. DOI=http://dx.doi.org/10.1145/2677199.2680587

55. Daniela K. Rosner. 2012. The material practices of collaboration. Proceedings of the ACM 2012 conference on Computer Supported Cooperative Work - CSCW '12: 1155. http://doi.org/10.1145/2145204.2145375

56. Magdalena Schmid, Sonja Rümelin, and Hendrik Richter. Empowering Materiality: Inspiring the Design of Tangible Interactions. 91-98.
57. Jin-min Seok, Jong-bum Woo, and Youn-kyung Lim. 2014. Non-finito products. Proceedings of the 32nd annual ACM conference on Human factors in computing systems - CHI '14, ACM Press, 693702. http://doi.org/10.1145/2556288.2557222

58. Michael Shorter, Jon Rogers, and John McGhee. 2014. Enhancing everyday paper interactions with paper circuits. Proceedings of the 2014 conference on Designing interactive systems - DIS '14: 39-42. http://doi.org/10.1145/2598510.2598584

59. Vygandas "Vegas" Šimbelis, Pedro Ferreira, Elsa Vaara, Kristina Höök, and Jarmo Laaksolahti. 2016. Repurposing Bits and Pieces of the Digital. $A C M$ CHI'16.

60. Jordi Solsona Belenguer. 2015. Engineering through Designerly Conversations with the Digital Material: The Approach, the Tools and the Design Space. Retrieved January 8, 2016 from http://kth.diva-

portal.org/smash/record.jsf?pid=diva2\%3A875831 \&dswid=2205

61. Joshua Tanenbaum, Karen Tanenbaum, and Ron Wakkary. 2012. Steampunk as design fiction. Proceedings of the 2012 ACM annual conference on Human Factors in Computing Systems - CHI '12: 1583. http://doi.org/10.1145/2207676.2208279

62. Robyn Taylor, Guy Schofield, Jonathan Hook, Karim Ladha, John Bowers, and Peter Wright. 2013. Crafting interactive systems. CHI EA '13, ACM Press, 3223. http://doi.org/10.1145/2468356.2479652

63. Vasiliki Tsaknaki, Ylva Fernaeus, and Martin Jonsson. 2015. Precious Materials of Interaction Exploring Interactive Accessories as Jewellery Items. Nordes'15 1, 6 .

64. Vasiliki Tsaknaki, Ylva Fernaeus, and Mischa Schaub. 2014. Leather as a material for crafting interactive and physical artifacts. In Proceedings of the 2014 conference on Designing interactive systems (DIS '14). ACM, New York, NY, USA, 514.

DOI=http://dx.doi.org/10.1145/2598510.2598574

65. John Turesson, Anxiao Chen, Erik Dahlström, Dan Carino, and Niclas Ericsson. 2015.The Memonile. Proceedings of SIDER'15, 162-164.

66. Anna Vallgårda and Ylva Fernaeus. 2015. Interaction Design as a Bricolage Practice. Proceedings of the Ninth International Conference on Tangible, Embedded, and Embodied Interaction - TEI '15: 173-180. http://doi.org/10.1145/2677199.2680594 
67. Anna Vallgårda and Tomas Sokoler. 2010. A Material Strategy: Exploring Material Properties of Computers. IJDesign 4, 3.

68. Mikael Wiberg. 2013. Methodology for materiality: interaction design research through a material lens. Personal and Ubiquitous Computing 18, 3: 625636. http://doi.org/10.1007/s00779-013-0686-7

69. Zoran, Amit and Leah Buechley. Hybrid Reassemblage: An Exploration of Craft, Digital Fabrication and Artifact Uniqueness. Retrieved August

24 , 2015 from http://web.media.mit.edu/ amitz/Publications_files/ Leonardo_HybridreAssemblage.pdf

70. Terry Irwin, Gideon Kossoff, and Cameron Tonkinwise. 2015. Transition Design: The Importance of Everyday Life and Lifestyles as a Leverage Point for Sustainability Transitions Academia.edu. Retrieved September 25, 2015 from http://www.academia.edu.

71. Snapchat. Retrieved from https://www.snapchat.com 